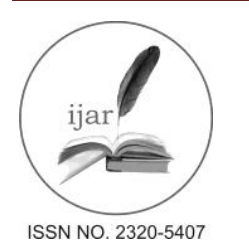
Journal homepage: http://www.journalijar.com

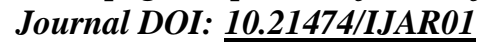

INTERNATIONAL JOURNAL

OF ADVANCED RESEARCH

RESEARCH ARTICLE

\title{
ANALYSIS BETWEEN THE TOURISM SECTOR AND ECONOMIC GROWTH IN AZERBAIJAN.
}

\author{
Dr. Sudabe SALIHOVA and Dr. Nurhodja AKBULAEV
}

Azerbaijan State Economic University, Turkish World Business Faculty, Economy and Business Department, Baku, Azerbaijan.

\section{Manuscript Info \\ Manuscript History: \\ Received: 22 April 2016 \\ Final Accepted: 17 May 2016 \\ Published Online: June 2016 \\ Key words: \\ Azerbaijan, Economic Growth, \\ Tourism and Economic Growth, \\ Analysis.}

*Corresponding Author

Sudabe SALIHOVA.

\section{Abstract}

Recently, tourism sector is in the spotlight of Azerbaijan amidst the non-oil sectors. Azerbaijan is in the wake of becoming tourism country and it seems that tourism has rapidly developed especially after 2000 years; the country tries to achieve a competitive advantage in international tourism sector. The key purpose of this research is to analyze the relation between the economic growth and tourism incomes in Azerbaijan based on the data covering 19902014 period and within the and cointegration tests.

The stationarity of model's variables has been provided with the first difference. According to the results of test made, availability of unilateral relation has been determined between tourism incomes and GDP. This result indicates that tourism is positively affected by the economic growth. According to the findings, it was defined that $1 \%$ increase in GDP has resulted almost with $4.2 \%$ increase of tourism incomes in researched period.

Copy Right, IJAR, 2016,. All rights reserved.

\section{Introduction:-}

Tourism is a sector which increase, improve and become global day by day. Despite the understanding of economic importance of tourism and its greater potential in this respect at the middle of 20th century, this sector has been ruled out generally in global researches made by 1950 years for the progress, growth and wealth (Crouch at al., 1999). In tandem with the end of second world war, tourism activities has started to develop especially in today's developed countries represented by western societies. Besides the understanding of its economic importance over time, tourism is one of rapidly developed sectors together with telecommunication and information technologies in the global economy of 21th century. Today, it is considered as one of the most essential sources for the economic growth and improvement in number of developed and developing countries (Diamond, 1977).

Tourism activities in Azerbaijan have entered into the growth trend in the last decade. It was observed that there is a considerably important progress in tourism sector related to the investments made and policies followed in this field especially since 2002s. Such developments are still underway. Tourism leads to important developments not only in economic field, but also in social and cultural fields in the period in question. Comparing to plenty of countries, Azerbaijan is known for its rich resources from the point of history, culture and natural beauties. Noteworthy to state that Azerbaijan has a great tourism potential with the facts that it owns 9 climates out of 11 in the world, unique natural beauties and clean sandy beaches and stable sunny days. Due to the fact that several historical cultures have prevailed in these lands, the country got the position of an outdoor museum. Besides that, cuisine culture and hospitality of people draws the attention of those who participate in international tourism activities.

According to the World Tourism Organization, number of international tourists has increased from 1.035 million in 2012 up to 1.087 million in 2013 by an increase of 52 million, and international tourism revenues have reached to 1.243 billion USD, in 2012 (UNWTO, 2014). If we assume that number of tourists were 25. 3 million in 1950, it is 
observed that world tourism steps have increased in $4296 \%$ (around forty three fold) within 63 years and signals a huge progress. It is predicted that afore mentioned figures will increase by 1.6 billion people and 2 trillion USD in 2020, and 2 billion people and 2.1 trillion USD, later in 2050. In addition to that, again in 2050, it is expected the worldwide total domestic and foreign incomes will reach to 24.2 trillion USD. Similarly according to the World Travel and Tourism Council (WTTC), more than 255 million people represented with $11 \%$ of whole work force around the world have been employed in tourism sector (Pizam, 1999). Therefore, tourism contributes significantly to employment, level of income, alleviation of local and international burden of debt, balance of payments, and consequently improvement of the level of welfare in a number of countries owning tourism potential, along with the developing countries at the top (Marcouiller at al., 2004).

Looking at Azerbaijan, it is noticed that there has been considerably high progress in tourism sector since 2003. Following the downfall of Soviet Union and gaining its independence, the process has been initiated for transition to the free market economy. No doubt that, implementation of state program on "Development of tourism sector in 2002-2005 years, at the Republic of Azerbaijan" has established favorable climate in result for the improvement of tourism within the rapid increase of tourism in the economy of Azerbaijan, and thus, laid the bases for the integration of country to the international tourism market (http://azerbaijans.com, 2014). Share of tourism in GDP of Azerbaijan has increased from 2, 86\% in 1995 to 3, 86\% in 2012; and share of tourism in export revenue has increased from $2,90 \%$ up to $9,62 \%$ in $2002-2012$.

While reviewing books and articles, despite the availability of some studies about other countries who investigated the relation between tourism and economic growth (Sharpley, 2002), it is seen that possible impact of such important sector over the economic growth of Azerbaijan has not been tested experimentally. Therefore, the prime purpose of study is to form a basis oriented to close this gap for Azerbaijan and tourism economy. And the second purpose is to test the availability of both mid and long term relation between the tourism and economic growth, and to present the possible contribution of this sector in respect to the economic growth. 3 hypotheses will be trialed to test the relation between the growth and tourism in economic development of country. The first one is the hypothesis that causes the economic growth of tourism, the second one is the hypothesis that leads to increase of economic growth in tourism and interact. In line with the purposes in question, previous empirical researches specified in books and examined the relation between the tourism and economic growth has been reviewed in the second part of study. The third part presents information on the method, model, variables and data used in study. And the fourth part indicates separately the consequences of all tests made with VAR (Vector Autoregressive) analysis, and includes the general assessment and comments on empirical results.

\section{Literature Review:-}

Export-oriented development strategy forms the basic resource of growth and economic development in a number of developing countries. Specially, following 1960, a number of less developed and developing countries changed their import substitution policies and started to stimulate export and preferred the export-oriented growth as economy policy. Looking at the economy literature, it is observed that there are a number of researches examining the casual relation between the export and economic growth (Bahar, 2006). There are similarities and differences of findings obtained by empirical studies made on relations between the revenues and economic growth of tourism. From the point of such similarities and differences, it is revealed that tourism, in the general sense export affects positively to economic growth, in other words, progress and increase in export results with proportional increase in economic growth (Shan and Sun, 1998: Bahar, 2006). Because, progress of export in country's economy means: to benefit from scale economies, to decrease foreign exchange restrictions and mitigate the foreign currency pressure, to provide positive externalities in non-trade sectors, to use effectively and efficiently the resources in order to achieve the competitiveness, to boost the investment in traditional sectors and consequently, affect positively to the economic growth (Mckınnon, 2004). From this point of view, it is possible to say that as a development strategy, theoretical basis indicating tourism to cause the economic growth is arising out of the export and economic growth literature (Vanegas at al., 2003). If we look at the related empirical studies in literature, results obtained from studies support tourism-oriented growth hypothesis, in general. According to the Panel Data, ARCH, Regression, Var and Granger analysis, studies obtained the availability of relation between the tourism revenues and economic growth are: Ghali (1976) Hawaii; Narayan and Prasad (2003) Fiji; Durbarry (2004) Mauritius; Aslan (2008) Turkey; Modeste (1995) Karayıp; Yıldırım and Ocal (2004) Turkey; Kasman and Kasman (2004) Turkey; Bahar (2006) Turkey; Bahar and Bozkurt (2010), GMM 21 countries; Chen and Chiou- Wei's (2009) Taiwan and South Korea. Also, according to the mentioned causality models, Kırbaş ve diğ. (2004) from Turkey defined the availability of unilateral causality from tourism to economic growth, Kizilgol and Erbayraklar (2008) from Turkey defined the 
availability of unilateral causality from economic growth to tourism revenues, Ongan and Demiroz (2005) from Turkey defined the availability of bilateral causality between the economic growth and tourism revenues both in long term and short term periods, Khalil and dig. (2007) from Pakistan defined strong relationship between the economic growth and tourism revenues. According to the findings by Oh (2005, Korea) and Yavuz (2006, Turkey), there is no relation between the tourism revenues and economic growth.

Except the afore mentioned studies, empirical studies researched relations between the tourism revenues, tourism expenditures, number of tourists, foreign exchange rates, international trade and GDP have been reviewed and related finding have been summarized. Webber (2001) from Australia has achieved the result that tourism demand is affected by the changes in exchange rate. Kulendran and Wilson (2000) from Australia have observed that there is a strong relationship between the international tourism and international trade. Shan and Wilson (2001) from China have observed that there is a strong relationship between the international tourism and international trade. Balaguer and Jorda (2002) from Spain consider that there is a mutual relationship between the exchange rate, tourism revenues and economic growth. Dritsakis (2004) from Greece consider that there is a relationship between the real exchange rate and real growth. Gunduz and Hatemi (2005) from Turkey consider that number of tourists and exchange rate have an impact on economic growth. Brida and dig. (2008) from Mexico believe that there is a relationship between the tourism expenditures, real exchange rate and real GDP.

\section{Econometric research method:-}

\section{Granger Causality Testing:-}

Standard Granger causality testing is a general approach for determination of the availability of causality relation between two (or more) variables. As the implementation of standard Granger causality testing is simple, it is used widely. During the empirical studies used especially the small examples with Guilkey- Salemi(1982) and GewekeMeese-Dent (1983) Monte Carlo have defined conformity of Granger causality test by the empirical studies used especially the small examples with simulations. Standard Granger causality test for 2 variables is as the following:

$$
\begin{aligned}
& Y_{t}=\alpha_{10}+\sum_{l=1}^{L_{11}} \alpha_{11 i} Y_{t-i}+\sum_{j=1}^{L_{12}} \alpha_{12 j} X_{t-j}+u_{1 t} \\
& X_{t}=\alpha_{20}+\sum_{l=1}^{L_{21}} \alpha_{21} Y_{t-1}+\sum_{j=1}^{L_{22}} \alpha_{22 j} X_{t-j}+u_{2 t} \\
& H_{o}: \quad \alpha_{12 j}=0 \quad j=1,2, . \quad \ldots, L_{12} \quad \text { için } \\
& H_{1}: \quad \alpha_{12 j} \neq 0 \quad \text { en } \quad \text { az } \quad \text { bir } j \quad \text { için }
\end{aligned}
$$

In function $1, \alpha_{10}$ is a fixed parameter, error term $\left(u_{1 t}\right)$ is a zero mean and fixed variance $\left[u_{1 t}-N D\left(0, \delta_{u}^{2}\right)\right]$ and white noise process. $L_{11}, L_{12}, L_{21}$ and $L_{22}$ are the optimal delay lengths defined based on one and more than one of criteria such as Akaike information criterion (AIC), Schwarz information criterion (SC), log-likelihood rate (LR). If we reject the basic hypothesis saying that the coefficient vector of delayed values of X variable isn't equal to zero, then $\mathrm{X}$ variable is a Granger cause of $\mathrm{Y}$ variable. Similarly, through the function 2 it is tested to know whether $\mathrm{Y}$ variable is a Granger cause of $\mathrm{X}$ variable or not. If the reject the basic hypothesis for both function (1) and (2), it is possible to mention two-sided causality relation. According to the results of hypothesis test, nonavailability of unilateral causality and causality relation is another possible case (Yavuz, 2005).

\section{Model And Data Set:-}

The main purpose of study is to test the availability of long term relation between tourism revenues and economic growth and to reveal the possible contribution of this sector to the economic growth. In a nutshell, as there is a positive impact of tourism revenues over the economic growth, hypothesis will be tested by this study. As in a number of studies specified in part 2, ie, in literature review, GDP grade will be used herein to measure the impact level of tourism on economic growth.

The difference from other studies is presented herein from the point of model estimate formed and tests used. Starting from this, quantity of relation between 2 series will be measured by using the time series of tourism 
revenues (TUR) and GDP. Statistical data covering 1990-2014 years on afore mentioned 2 variables have been obtained from database of the Ministry of Tourism of Azerbaijan, State Statistic Commitee, Central Bank of Azerbaijan and the World Bank, and all variables have been expressed as napierian logarithm. Data related to the tourism revenues of 1990-1994 consist of estimated values. VAR method will be used to measure the relation between 2 series mentioned.

\section{Empirical results \\ Unit Test Results:-}

It is required to make the stationarity tests of series prior to the research of causality relation. This is because the method for realization of causality analysis changes based on provision of stationarity of series. Regression analysis cause high test statistics and spurious regression in non-stationary series.

In other words, variables not containing actual relation between each-other may be seen as containing relation between each-other. Therefore, the first point in analysis during the usage of time series is to define whether the variables used in model are stationary or non-stationary. A time series, time average and variance doesn't change within the time and will be stationary when the mutual variance between these 2 period is linked not to the calculation period of common variances, but only to the distance between two periods. (Gujurati, 2004).

Tourism revenues have been indicated with TG variance, and gross domestic product has been specified with GDP in analysis. ADF roof test results related to variable has been presented in Table 2 as fixed, fixed-trendy, non-fixeduntrendy. While reviewing the Table 2, through the unit roof test results made in high level for both variable it becomes clear that variables are non- stationary. Again, ADF test has been performed to define whether the variables are stationary or non-stationary in their first differences. According to the test results provided in Table 2 , zero hypotheses contained in unit root of the first difference of variables has been rejected with $1 \%$ relevance level. Thus, it was concluded that variables are stationary in their first difference I (1).

Table 2:- ADF Unit Root Test Results

\begin{tabular}{|c|c|c|c|}
\hline \multirow{2}{*}{ Variables } & \multicolumn{3}{|c|}{ ADF } \\
\cline { 2 - 4 } & Fixed & Fixed and Trendy & Non-fixed and untrendy \\
\hline $\ln$ TG & $-0,4508$ & $-4,3338$ & 0,8466 \\
\hline $\ln$ GSYİH & 0,4169 & $-1,0146$ & 2,1723 \\
\hline $\mathrm{d}(\ln$ TG) & $-4,0241^{*}$ & $-4,3131^{* *}$ & $-3,6283^{*}$ \\
\hline $\mathrm{d}(\ln$ GSYİH) & $-2,2621$ & $-2,5313$ & $-1,6085^{* *}$ \\
\hline
\end{tabular}

Note: As a result of ADF test, if the value of $\mathrm{p}$ is more than 0,05 then there is a unit root. Otherwise, it will be concluded that unit root isn't available. * indicates that coefficients are meaningful with $1 \%$ level and $* *$ indicates that coefficients are meaningful with $1 \%$ level.

In their first differences it is required to define delay length eligible for the future analysis in stationary series. As also indicated in Table 3 below, the analysis conducted for the determination of the length of eligible delay in model, eligible delay length has been determined by application of criteria such as LR (Likelihood), FPE (Final Prediction Error), AIC (Akaike Information Criterion), SC (Shwarz Information Criterion), HQ (Hannan-Quinn Information Criterion). Therefore, it was estimated that length of eligible delay is equal to 2 in all of information criterion. Length of delay will be used as 2 in analysis.

Table 3:- Determination of eligible delay length.

\begin{tabular}{ccccccc}
\hline \hline Lag & LogL & LR & FPE & AlC & SC & HQ \\
\hline \hline 0 & -53.66595 & NA & 0.540593 & 5.060541 & 5.159726 & 5.083906 \\
1 & 3.285385 & 98.37048 & 0.004403 & 0.246783 & 0.544340 & 0.316879 \\
2 & 9.759215 & $10.00501^{\star}$ & $0.003561^{\star}$ & $0.021890^{\star}$ & $0.517818^{\star}$ & $0.138715^{\star}$ \\
3 & 11.89019 & 2.905870 & 0.004347 & 0.191801 & 0.886101 & 0.355357 \\
\hline \hline
\end{tabular}

Note: * indicates the number of eligible delay in accordance with the related criterion.

Granger Causality Cointegration Test:- 
According to the Granger, if the TG variable contributes positively to the GDP series while being added to mode, in other words, if TG variable increase its predictability, then TG is the cause of GDP. Such case is tested by F value achieved with proportion of the residues of limited model and residues of unlimited model. If the addition of GDP variable to model affects positively to its series, in other words, it is increase the predictability, then the GDP is the cause of TG (Granger,1969). Similar test logistic is effective for the last 2 case, as well.

Table 4:- Grander Causality Table

\begin{tabular}{|c|c|c|c|}
\hline \multicolumn{4}{|c|}{$\begin{array}{l}\text { Data Period:1990-2014 } \\
\text { Length of delay: } 2 \text { (According to SC) }\end{array}$} \\
\hline $\mathrm{H}_{0}$ Hipotesys & Data & F value & P değeri \\
\hline $\begin{array}{l}\text { lnTG isn't the cause of lnGDP's } \\
\text { Grander }\end{array}$ & 23 & 0,1975 & 0.9059 \\
\hline \begin{tabular}{|l} 
lnGDP's is the cause of $\ln T G$. \\
\end{tabular} & & 6.26749 & $0.0400^{*}$ \\
\hline
\end{tabular}

* indicates that hypothesis has been rejected with 5\% semantic level.

Granger causality test indicated in Table 4 has been estimated from the second delay. If we look at the mentioned Table which indicates the availability or non-availability of causality relation between the variables, the hypothesis of "tourism revenues don't have impact on GDP" is accepted in 5\% importance level. From the other point of view, availability of the impact of GDP over the tourism revenues within the content of Grander causality can be seen again from the same Table. Increase of GDP results with the increase of tourism revenues. Within the content of Granger causality, it should be understood that causality relation between the tourism revenues and economic growth is prone from the economic growth towards the revenues. In other words, economic development and growth in Azerbaijan cause the increase of tourism revenues.

Briefly, according to the results of causality tests made, availability of unilateral causality relation oriented from GDP to the tourism revenues can be seen. In this way, economic growth in Azerbaijan results with the increase of tourism revenues within the content of Granger causality.

Availability or non-availability of long term relation between GDP and tourism revenues should be investigated. Availability of long term balance relation between the time series is investigated through the cointegration tests. In this study, availability of long term relations between the GDP and TG variables has been investigated through Engle-Granger cointegration method. For this, stationarity of residuals in level values is investigated. If the residuals are stationary in level values, then it is concluded that our variables are co-integrated. According to the results of Engle-Granger cointegration test, availability of long term relation between the variables is accepted with 5\% semantic level in case of GDP to be dependent variable, and with $1 \%$ semantic level in case of TG to be dependent variable.

Test results show that GDP and tourism revenues act together within the long period. And it reveals that economic growth in Azerbaijan has an impact on the tourism revenues during the long period. In other words, there is a long term relation between 2 variables in question.

\section{Results and Inputs:-}

The main purpose of this study is to analyze the relation between the economic growth and tourism revenues in Azerbaijan within the causality and cointegration tests and with the data covering 1990-2014 periods. Stationary of model's variables has been provided with the first difference. According to the results of causality test made, availability of unilateral causality relation between the tourism revenues and GDP has been confirmed. This outcome indicates that tourism is affected positively by the economic growth. Due to findings, it was defined that $1 \%$ increase in GDP results with $4.2 \%$ increase in tourism revenues during the period studied. Availability of long term relationship between 2 variables has been achieved Based on the results of co integration test. It was concluded that when the GDP is dependent variable with 5\%, and when the TG is dependent variable with $1 \%$, these variables are co-integrated in semantic level. Results achieved show that economic growth in Azerbaijan affected the tourism revenues in long period. Thus, this study conducted for Azerbaijan defines that economic growth and development in long period affect tourism sector. 
Finally, some comments should be made on the limits of this study. As the variables used in the model developed, the GDP variable represents the economic growth and tourism variable represents tourism revenues. These 2 variables and applied methods form the limits of study. It would be eligible to test the results achieved by adding additional factors to the model in question. In this context, some other variables which is estimated to affect the growth may be included to the model, or a different model may be used in future studies. Thus, doubts to be emerged on the economic meaning of results achieved may be removed.

\section{References:-}

1. Alper Aslan (2008). Economic Growth and Econometric Analysis on Tourism in Turkey Relations, Institute of Social Sciences Magazine Issue 24 Y 1: 1-11.

2. Bahar Ozan (2006). Turkey's tourism sector Impact on the Economic Growth: VAR Analysis Approach, Management and Economics, Volume: 13, Issue: 2, Celal Bayar University I.I.B.F. Manisa, 138.

3. Balaguer, J. and Jordan, M.C. (2002). Tourism as a Long-run Economic Growth Factor: the Spanish Case, Applied Economics, 34, 877-884.

4. Britton, S. G. (1982). The Political Economy of Tourism in the Third World, Annals of Tourism Research, 9, 332.

5. Cho, V. (2003). Comparison of Three Different Approaches to Tourist arrivalforecasting, Tourism Management, 24, 323-330.

6. Copeland, B.R. (1991). Tourism, Welfare and De-industrialization in a Small Open Economy, Economica, 58, November, 515.

7. Crouch, G.I. and Ritchie, J.R.B. (1999). Tourism, Competitiveness and Prosperity societal, Journal of Business Reseacrh, 44. 138.

8. Diamond, J. (1977). Tourism's Role in Economic Development: the Case Reexamined, Economic Development and Cultural Change, 25 (3), 539.

9. Durbarry, R. (2004). Tourism and Economic Growth: the Case of Mauritius, Tourism Economics, 10, 389401.

10. Engle, R. Grange, J. (1987). Cointegratio's and Error Correction: Representation, Estimation and Testing, Econometrica, 50, 987-1007.

11. Erdal Atuker. (2011). New Approaches to Granger-causality test, Ataturk University. Administration Journal, 10 Econometrics and Statistics Symposium Special Edition, 137-153.

12. Erdal Demirhan, Growth and Causality Between Exports: The Case of Turkey, Ankara University Faculty of Political Sciences Journal 60-4, 75-88.

13. Göymen K. (2000). Tourism and Governance in Turkey, Annals of Tourism Research, 27 (4), 1025-1048.

14. Granger, C. W. J. (1969). Investigating Causal Relations by Econometric Models and Cross-Spectral Methods, Econometrica 37, 553-560.

15. Greene, W.H. (1993). Econometric Analiysis, Second Edition, Prentice-Hall.

16. Hao, J., Yes, T. and Cho, J. (2003). A Forecasting Model of Tourist Arrivals to Thailand From Major Markets, Tourism Analysis, 8, 33.

17. Celebration, A. (2000). Econometric Time Series, Ankara Gazi Bookstore, 1-13.

18. Marcouil are D.W., K_M, K.K. and Del are S.C. (2004). Natural Amenities, Tourism and Income Distribution, Annals of Tourism Research, 31 (4). 1031-1050.

19. Mckinnon, T. (1964). Foreign Exchange Constraint of Economic Development Aid Allocation and Efficient Economic Journal, 74, 388-409.

20. Pizam, A. (1999). Life and Tourism in the Year 2050, International Journal of Hospitality Management, 18, 331-343.

21. Sharpley, R. (2002). The Challenges of Economic Diversification Through Tourism: the Case of Abu Dhabi, The International Journal of Tourism Research, 4 (3), May / June, 221-235.

22. The last 10 years, the development of the tourism sector, http://azerbaijans.com/content_1037_tr.html Accessed: $30 / 01 / 2014$

23. Vanegas, M. and Croes, R.R. (2003). Growth, Development and Tourism in a Small Economy: Evidence from Aruba, The International Journal of Tourism Research, 5 (5), September / October, 315-330.

24. Volcano Alptekin, Sustainable Economic Growth Performance Development Perception of Meaning Impact on Tourism Industry: The Case of Turkey, Selcuk University Journal of the Institute of Social Sciences • 28/2012, p. 31-41. 


\section{Web sites:-}

1. http://www.mct.gov.az

2. http://www.stat.gov.az

3. http://abc.az/rus/news/32098.html

4. http://az.apa.az/news/291833

5. http://azerbaijans.com/content_1774_ru.html

6. http://azerbaijans.com/content_892_ru.html

7. http://www.azstat.org/

8. The World Bank http://data.worldbank.org/country/azerbaij

9. World Tourism Organization UNWTO http://media.unwto.org 2014

10. APA, the number of employees in the tourism sector increased by 3 times in the last 9 years, http://az.apa.az/news/291833

11. The market of international tourism: the main trends in 2013, http: //xn--b1ae2adf4f.xn-p1ai/analytics/research/7035-turizm.html

12. Tourism in Azerbaijan, http://ru.wikipedia.org/wiki 